\title{
Persepsi Masyarakat Tentang Persahabatan dalam Film 5 cm (Studi Deskriptif Pada Siswa SMK Negeri 1 Barumun Padang Lawas)
}

\section{Community Perception of Friendship in $5 \mathrm{~cm}$ Film (Descriptive Study on Students of SMK Negeri 1 Barumun Padang Lawas)}

\section{Sri Rizki Kurnia Dalimunthe1), Yan Hendra'2) \& Armansyah Matondang1)}

\author{
1) Program Studi Ilmu Komunikasi, Fakultas Ilmu Sosial dan Ilmu Politik, \\ Universitas Medan Area, Indonesia \\ 2) Program Studi Ilmu Komunikasi, Fakultas Ilmu Sosial dan Ilmu Politik, \\ Universitas Muhammadiyah Sumatear Utara, Indonesia
}

Diterima: 27 Mei 2019; Disetujui: 21 September 2019; Diterbitkan: 6 Januari 2020.

\begin{abstract}
Abstrak
Penelitian ini mengambil tema dari sebuah film berjudul Persepsi Masyarakat tentang Persahabatan dalam film 5 $\mathrm{Cm}$. Penelitian ini bertujuan untuk melihat nilai-nilai yang ada dalam film $5 \mathrm{Cm}$ dan untuk mengetahui dalam persepsi tentang persahabatan dalam film $5 \mathrm{Cm}$ yang mencakup nilai-nilai kesetiaan, perjuangan, ketulusan, keakraban, saling membantu, pengorbanan dan kerja keras. Metode yang digunakan dalam penelitian ini adalah metode kuantitatif deskriptif. Objek penelitian adalah persepsi masyarakat terhadap film $5 \mathrm{Cm}$ dengan pendekatan teori persepsi. Untuk penentuan jumlah responden penelitian ini menggunakan populasi dan sampel. Populasi dalam penelitian ini adalah siswa SMK Negeri 1 Barumun Padang Lawas yang berjumlah 360 orang seluruh kelas X, XI, XII jurusan Teknik Komputer dan Jaringan (TKJ) SMK Negeri 1 Barumun. Dan teknik penarikan sampel yang digunakan dalam penelitian ini adalah Purposive Sampling dengan mengambil sampel sebanyak 40 orang atau $10 \%$ dari jumlah populasi. Teknik pengumpulan data yang digunakan adalah dengan menyebar angket, studi kepustakaan dan dokumentasi. Teknik analisis data pada penelitian ini teknik analisis data menggunakan metode deskriptif yaitu dengan cara mendeskripsikan serta menjelaskan data yang diperoleh selama penelitian. Hasil penelitian ini menunjukkan bahwa film $5 \mathrm{Cm}$ adalah film yang memberikan manfaat kepada masyarakat. Mayoritas siswa memiliki persepsi yang cenderung positif tentang nilai-nilai persahabatan yang ada dalam film 5 $\mathrm{Cm}$.

Kata Kunci: Persepsi, Persahabatan, Film 5 Cm, Komunikasi Massa
\end{abstract}

\section{Abstract}

This study takes the theme of a film titled Public Perceptions of Friendship in the film $5 \mathrm{Cm}$. This study aims to look at the values that exist in the film $5 \mathrm{~cm}$ and to know the perception of friendship in the film $5 \mathrm{~cm}$ which includes the values of loyalty, struggle, sincerity, solidarity, mutual help, sacrifice and hard work. The method used in this research is descriptive method. The object of research is the public perception of the film $5 \mathrm{Cm}$ with perception theory approach. To determine the number of respondents of this study using the sample population. The population in this study were students of SMK Negeri 1 Barumun Padang Lawas, amounting to 360 people throughout the class X, XI, XII Department of Computer Engineering and Networks (TKJ) of SMK Negeri 1 Barumun. And sampling techniques used in this research is purposive sampling by taking a sample of 40 people or $10 \%$ of the total population. Data collection techniques used is to spread out the questionnaire, literature study and documentation. Data analysis techniques in the study of data analysis techniques using descriptive method by describing and explaining the data obtained during the study. These results indicate that the film $5 \mathrm{Cm}$ is a film that provides benefits to the community. The majority of students have a perception that tend to be positive about the values of friendship that exist in the film $5 \mathrm{Cm}$.

Keywords: Perception, Friendship, Movie 5 Cm, Mass Communicatin

How to Cite: Dalimunthe S.R.K, Hendra, Y \& Matondang, A (2020). Persepsi Masyarakat Tentang Persahabatan dalam Film $5 \mathrm{~cm}$ (Studi Deskriptif Pada Siswa SMK Negeri 1 Barumun Padang Lawas). PERSPEKTIF, 9 (1): 38-45.

*Corresponding author:

E-mail: sririzkikurniadlt@yahoo.com ISSN 2085-0328 (Print) ISSN 2541-5913 (Online) 


\section{PENDAHULUAN}

Perkembangan teknologi informasi kini berjalan begitu pesat dengan ditemukannya berbagai macam sarana informasi seperti alat cetak, radio, televisi hingga internet. Semua itu bertujuan untuk menunjang keinginan manusia untuk mendapatkan suatu informasi yang dapat mereka gunakan untuk berbagai kepentingan yang sifatnya mendasar. Semakin pesatnya kemajuan teknologi informasi menimbulkan perkembangan untuk membangun dunia secara universal. Hal ini menyebabkan terbentuknya komunikasi massa yang merupakan suatu tipe komunikasi yang mampu melipatgandakan pesan-pesan komunikasi. Komunikasi massa dapat dipahami sebagai komunikasi yang menggunakan media massa untuk menyampaikan pesan.

Dari komunikasi massa terdapat istilah media massa. Media massa merupakan saran komunikasi massa di mana terjadinya proses penyampaian pesan, gagasan atau informasi kepada orang banyak (publik) secara serentak dengan menggunakan alat-alat komunikasi seperti surat kabar, film, radio dan televisi. Media massa dapat mempengaruhi pikiran, perasaan dan perilaku seseorang serta secara perlahan dapat membentuk pandangan seseorang terhadap suatu hal. Setiap jenis media massa memiliki pengaruh yang berbeda. Salah satu jenis media massa yang cukup efektif adalah film. Film sebagai salah satu bentuk media massa, merupakan salah satu representasi yang ada dalam masyarakat. Film merupakan media komunikasi yang memiliki kekuatan tersendiri dalam menyampaikan makna. Melalui film, berbagai pesan dapat disampaikan kepada audience yang di inginkan. Kebudayaan, nilai-nilai sosial, adat-istiadat, pengalaman, teknologi, dan bahasa dapat disampaikan secara holistik. Proses pesan yang dilakukanpun efektif dan efisien karena melibatkan semua panca indra baik audio maupun visual layaknya medium televisi dan memerlukan waktu yang lebih singkat dibandingkan membaca buku.

Film juga merupakan bentuk pesan yang terdiri dari berbagai tanda dan simbol yang membentuk sebuah sistem makna sehingga bisa diinterpretasikan oleh orang secara berbeda- beda, tergantung kepada referensi dan kemampuan berpikir orang tersebut. Sebagai media massa, film digunakan sebagai media yang merefleksikan realitas atau bahkan membentuk realitas. Film mengkomunikasikan pesan dari pembuat film (film maker) kepada penonton (audience) yang mengandung aspek hiburan serta memuat pesan edukatif.

Perkembangan perfilman juga terjadi di Indonesia dengan munculnya berbagai genre yang meramaikan variasi perfilman. Akhir tahun 2012 lalu perfilman Indonesia diramaikan oleh film-film tentang drama baik tentang persahabatan ataupun tentang percintaan. Seperti film Rizal Mantovani yang berjudul $5 \mathrm{Cm}$. Film berjudul $5 \mathrm{Cm}$ ini menceritakan persahabatan antara lima pemuda yang bernama Genta (yang diperankan Fedi Nuril), Arial (diperankan Denny Sumargo), Zafran (Herjunot Ali), Riani (Raline Shah) dan Ian diperankan oleh (Igor Saykoji). Film ini bercerita tentang sebuah persahabatan yang terjalin selama sepuluh tahun dan suatu hari mereka merasakan jenuh dengan persahabatan mereka sehingga mereka memutuskan untuk tidak bertemu dan berkomunikasi selama tiga bulan. Setelah tiga bulan berselang mereka merayakan pertemuan dengan perjalanan penuh dengan tantangan yaitu sebuah perjalanan hati dengan mengibarkan Sang Saka Merah Putih dan mendaki di gunung tertinggi di Jawa yaitu Semeru pada tanggal 17 Agustus. Film ini juga mempunyai makna tersendiri yaitu hati untuk mencintai persahabatan yang erat dan hati untuk mencintai negeri ini. Segala rintangan dapat mereka hadapi bersamasama, karena mereka memiliki impian. 
Secara keseluruhan film $5 \mathrm{Cm}$ ini merupakan film yang sangat menarik karena selain sarat akan pesan moral dan nilai-nilai sosial juga memiliki kekuatan untuk memotivasi penonton agar percaya pada kekuatan mimpi. Persahabatan yang begitu berharga bagi diri mereka. Sahabat merupakan salah satu anugerah terindah yang pernah ada di dalam dunia kita, seseorang pasti akan membutuhkan teman yang bisa berbagi di saat susah maupun senang. Sahabat memiliki peran yang bisa membuat hidup menjadi lebih berwarna dan membantu memecahkan permasalahan yang dihadapi atau hanya sekedar membicarakan masalah pekerjaan atau kehidupan yang ada di sekitar kita. Sahabat akan berbagi cerita yang lucu dan bisa membuat kedekatan dengan sahabat. Dalam persahabatan ini terdapat nilai-nilai yang menonjol yaitu nilai kesetiaan, pengorbanan, perjuangan, keakraban, ketulusan, kerja keras, dan saling membantu. Nilai-nilai inilah yang akan peneliti angkat dalam penelitian ini.

Film $5 \mathrm{Cm}$ mengangkat tema tentang persahabatan karya Donny Dhirgantoro ini merupakan salah satu film best seller yang banyak menginspirasi para pembaca dan penonton. Film ini juga memaparkan bagaimana kekuatan mimpi itu mampu mengubah diri seseorang menjadi manusia yang lebih memaknai hidup dan masih tetap berjuang meskipun dihadapkan pada kesulitan-kesulitan di dalam kehidupan. Judul film ini sangat unik dan pendek tapi memiliki cerita yang sangat menyentuh. Film lebih dianggap sebagai media hiburan ketimbang media pembujuk. Namun yang jelas, film sebenarnya punya kekuatan bujukan atau persuasi yang besar.

\section{METODE PENELITIAN}

Jenis penelitian yang digunakan dalam penelitian ini adalah penelitian deskriptif. Metode deskriptif dapat diartikan sebagai prosedur pemecahan masalah yang diselidiki dengan menggambarkan atau melukiskan keadaan subjek/objek penelitian, baik itu seseorang, lembaga, masyarakat dan yang lainnya pada saat sekarang, berdasarkan fakta-fakta yang tampak atau sebagaimana adanya (Nawawi, 1995).

Metode deskriptif bertujuan untuk melukiskan secara sistematis karakteristik populasi atau bidang-bidang tertentu secara faktual dan cermat tanpa mencari atau menjelaskan suatu hubungan (Jalaluddin, 2002). Dalam penelitian untuk pengumpulan data dengan menggunakan populasi dan sampel yaitu: Jumlah populasi sebanyak 360 seluruh siswa kelas X, XI, dan XII TKJ SMK Negeri 1

Barumun. Teknik penarikan sampel yang digunakan adalah Purposive Sampling. Purposive Sampling adalah pengambilan sampel yang disesuaikan dengan tujuan penelitian, dimana sampel yang terpilih sesuai dengan kriteriakriteria yang ditetapkan berdasarkan tujuan penelitian (Kriyantono, 2006).

Adapun kriteria sampelnya adalah: a) Siswa SMK Negeri 1 Barumun Padang Lawas yang terdaftar dan masih aktif, pada jurusan Teknik Komputer dan Jaringan (TKJ) kelas X, XI, dan XII. b. Siswa yang telah menonton film $5 \mathrm{Cm}$.

Berdasarkan pendapat tersebut, maka peneliti mengambil sampel sebanyak 40 orang atau $10 \%$ dari jumlah populasi 360 seluruh Siswa kelas X, XI dan XII TKJ SMK Negeri 1 barumun.

Sumber Data dan Teknik Pengumpulan Data. Dalam penelitian ini sumber data primer berupa jawaban yang diperoleh dari angket/quesioner dengan para responden yang telah ditentukan yang meliputi berbagai hal yang berkaitan dengan persepsi masyarakat tentang persahabatan dalam film $5 \mathrm{Cm}$ sedangkan sumber data sekunder dalam penelitian ini berupa pendapat siswa, daftar nama siswa yang memberikan pendapat, profil lokasi yang akan diteliti, serta foto-foto. 


\section{HASIL DAN PEMBAHASAN}

Berdasarkan hasil penyebaran angket yang telah dilakukan, dapat diketahui bahwasanya semua responden memiliki persepsi dalam film $5 \mathrm{Cm}$. semua responden memiliki cara pandang yang berbeda-beda. Perspektif yaitu cara pandang kita terhadap sudut pandangan. Cara kita memandang atau pendekatan yang kita gunakan dalam mengamati kenyataan dan menentukan pengetahuan yang kita gunakan. Dalam proses penelitian yang telah diamatin. Bentuk persepsi merupakan bagian dari keseluruhan proses yang menghasilkan tanggapan setelah rangsangan diterapkan kepada manusia, adalah pengenalan, penalaran, perasaan dan tanggapan yang terjadi dalam responden. Persepsi merupakan proses yang terjadi dalam kegiatan organisasi dan menafsirkan rangsangan dalam film $5 \mathrm{Cm}$ yang terjadi di lingkungan kita, dan proses tersebut mempengaruhi perilaku responden yang telah menonton film $5 \mathrm{Cm}$ secara tanpa disadari responden. Pemain dalam film 5 $\mathrm{Cm}$ juga menjiwai seluruh adegan, sehingga penghayatan peran yang dimainkan para pemain dapat secara langsung dirasakan oleh penonton yang terhanyut terbawa situasi dan kondisi cerita tersebut.

Proses Menerima Rangsangan, adalah menerima rangsangan atau data dari berbagai sumber. Kebanyakan data diterima melalui panca indera. Kita melihat sesuatu, mendengar, mencium, merasakan atau menyentuhnya, sehingga kita mempelajari segi-segi lain dari sesuatu. Dari semua responden yang terjadi adalah merasakan efek dari proses rangsangan yang terjadi setelah menonton film $5 \mathrm{Cm}$, yang terjadi secara langsung.

Proses Menyeleksi Rangsangan, yaitu setelah diterima rangsangan atau data seleksi. Tidaklah mungkin memperhatikan semua rangsangan yang diterima. Demi menghemat perhatian yang digunakan, rangsangan itu disaring atau diseleksi untuk diproses lebih lanjut. Responden menerima rangsangan dengan baik dan tidak semua persepsi yang diambil dalam film $5 \mathrm{Cm}$ menurut responden dalam film 5 $\mathrm{Cm}$ ada hal-hal yang tidak perlu diperhatikan dan diamati. Karena tidak semua memiliki nilai-nilai yang positif untuk patuh dicontohkan. Misalnya dalam setiap hal yang dilakukan pasti ada positif maupun yang negatif. Dari segi positif film tersebut memotivasi setiap penonton untuk menjaga hubungan persahabatannya.

\section{Proses}

pengorganisasian,

Rangsangan yang diterima selanjutnya diorganisasikan dalam suatu bentuk. Ada tiga dimensi utama dalam pengorganisasian rangsangan yakni: (Pengelompokan) pengelompokan yang terjadi pada responden terjadinya rangsangan yang diterima dikelompokkan masing-masing film $5 \mathrm{Cm}$ dianggap sebagai film sangat bagus untuk pembentukan kelompok. Dan menceritakan kehidupan persahabatan yang terjalin dalam berbeda karakter, suka duka dijalani bersama.

Menurut peneliti proses yang terjadi adalah yang dirasakan responden masingmasing walapun persepsi yang terjadi ada yang sama dan ada yang berbeda dalam fikiran. Persepsi responden adalah persepsi muncul karena setiap penilaian dan pemilihan seseorang terhadap orang lain diukur berdasarkan penyertaan budaya sendiri. Komunikasi akan mencapai kualitas hasil komunikasi yang diharapakan. Dalam pengertian yang sederhana, persepsi yaitu saat di mana setiap individu memilih, mengevaluasi dan mengorganisasikan rangsangan atau stimuli yang terjadi berdasarkan dari dunia luar.

Proses

Penafsiran, setelah rangsangan atau data diterima dan diatur, si penerima lalu menafsirkan data itu dengan berbagai cara. Dikatakan bahwa telah terjadi persepsi setelah data ditafsirkan. Persepsi pada dasarnya memberikan arti pada data dan informasi 
yang diterima. Pesan persahabatan dalam kehidupan menjadi motivasi responden dan panutan juga untuk menjaga kekompakan persahabatan responden tentang betapa pentingnya persahabatan menurut responden dalam kehidupan sehari-hari, film $5 \mathrm{Cm}$ juga menyadarkan responden untuk tidak menyerah dengan apa yang diinginkan dan terus berusaha hingga menggapainya dengan baik.

Proses pengecekan, setelah data ditafsirkan si penerima mengambil tindakan untuk mengecek penafsirannya benar atau salah. Hampir dari 40 responden mengatakan bahwa film $5 \mathrm{Cm}$ sempurna dan banyak mengandung nilainilai yang bermakna.

Proses reaksi, tahap terakhir adalah tindakan sehubungan dengan apa yang telah diserap. Hal ini biasanya dilakukan jika seseorang bertindak sehubungan dengan persepsinya. Film $5 \mathrm{Cm}$ merupakan film yang diangkat dari kisah persahabatan, yang menjadi bagian dari diri kita dan persahabatan membuat

\begin{tabular}{|c|c|c|c|}
\hline No & Alternatif Jawaban & Frekuensi & $\%$ \\
\hline 1 & $\begin{array}{l}\text { Pengorbanan } \\
\text { ikhlas }\end{array}$ & yang23 & 57,5 \\
\hline 2 & $\begin{array}{l}\text { Pengorbanan } \\
\text { penuh dengan tanta }\end{array}$ & $\begin{array}{l}\text { yang13 } \\
\text { angan }\end{array}$ & 32,5 \\
\hline \multirow[t]{2}{*}{3} & $\begin{array}{l}\text { Pengorbanan } \\
\text { terpaksa }\end{array}$ & yang4 & 10 \\
\hline & Total & 40 & 100 \\
\hline
\end{tabular}

hubungan menjadi lebih baik dan
membentuk tali persaudaraan yang tidak terputuskan. Film memiliki daya tarik masing-masing orang, karena tanggapan setiap orang pasti berbeda-beda. Film 5 $\mathrm{Cm}$ ini memberikan pelajaran yang berharga, salah satunya adalah kekompakkan dalam mempererat persahabatan. Dukungan para sahabat sangat memberikan motivasi dalam kehidupan sehari-hari. Film $5 \mathrm{Cm}$ ini telah berhasil menggambarkan hubungan persahabatan yang erat dalam kurung waktu yang lama.
Dari tabel di atas menunjukkan data penilaian responden tentang nilai kesetiaan yang terkandung dalam film 5 $\mathrm{Cm}$. Jumlah responden yang menjawab ada nilai kesetiaan yang sejati dalam film tersebut sebanyak 30 orang (75\%), sedangkan responden yang menjawab kesetiaan yang pura-pura adalah sebanyak 4 orang (10\%) dan 6 orang (15\%) responden menyatakan ada nilai kesetiaan yang biasa saja dalam film $5 \mathrm{Cm}$.

Dalam film $5 \mathrm{Cm}$ juga terdapat nilai pengorbanan. Pengorbanan adalah suatu tindakan seseorang yang ikhlas dalam bentuk pertolongan dan tidak berharap imbalan dari apa yang sudah dilakukannya. Terutama pada film $5 \mathrm{Cm}$ ini terdapat pengorbanan ketika mereka sudah melakukan perjalanan, mereka dituntut untuk tidak gengsi jika sudah tidak kuat melangkah lagi, dan sahabat yang lainnya akan mendekat, menolong, memeluk, seperti ketika Azriel merasa kedinginan yang hebat bagai tertusuk jarum. Seperti ketika Zafran kakinya terluka, Ian yang hampir mati terkena benturan runtuhan batu, semua terluka dan hampir putus asa. Disitu kita menilai bahwa ada pengorbanan yang begitu luar biasa dalam persahabatan ini. Dari cerita tersebut jelas bahwa nilai pengorbanan dalam film $5 \mathrm{Cm}$ memang ada nilai pengorbanan yang ikhlas dan penuh dengan tantangan.

Tabel 4.2 Nilai Pengorbanan Yang Terkandung Dalam Film $5 \mathrm{Cm}$

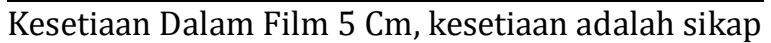

No Alternäif Jawäban $\quad$ Frekuensi \%

1 Kesetiaan yang sejati $30 \quad 75$

2 Kesetiaan yang pura-pura $4 \quad 10$

3 Kesetiaan yang biasa saja $6 \quad 15$

$\begin{array}{lll}\text { Total } & 40 & 100\end{array}$

Dari tabel di atas menunjukkan data penilaian responden tentang nilai pengorbanan yang terdapat dalam film 5 $\mathrm{Cm}$. Jumlah responden yang menjawab ada pengorbanan yang ikhlas dalam film $5 \mathrm{Cm}$ sebanyak 23 orang $(57,5 \%)$, sedangkan responden yang menjawab pengorbanan 
yang penuh dengan tantangan adalah sebanyak 13 orang $(32,5 \%)$ dan 4 orang (10\%) responden menyatakan pengorbanan yang terpaksa. Dengan demikian dapat disimpulkan bahwa mayoritas responden dalam penelitian ini menyatakan terdapat nilai pengorbanan yang penuh ikhlas dalam film $5 \mathrm{Cm}$. Hal ini ditunjukkan dengan persentase sebesar $(57,5 \%)$ atau dijawab sebanyak 23 orang.

Nilai perjuangan juga terdapat pada film $5 \mathrm{Cm}$. Perjuangan adalah usaha kerja keras seseorang untuk meraih apa yang di inginkannya tanpa ada kata mengeluh sampai apa yang di inginkannya tercapai dan terpenuhi. Jika dikaitkan dengan film 5 $\mathrm{Cm}$ ini ada perjuangan yang begitu kuat untuk mencapai puncak gunung Mahameru, perjalanan yang penuh dengan perjuangan meskipun dihadapkan pada rintangan dan kesulitan yang begitu berat dan hampir putus asa tetapi mereka tetap saling menyemangati satu sama lain dan mereka selalu percaya bahwa mereka pasti bisa karena mereka tetap berjuang dan tidak pernah menyerah sampai menuju pada puncaknya.

Nilai keakraban dalam film $5 \mathrm{Cm}$ sangatlah menonjol untuk para penontonnya karena dengan keakraban yang dijalin dalam persahabatan ini keakraban yang yang sangat kompak. Keakraban adalah hubungan yang dekat yang dijalani antara seseorang dengan seseorang lainnya dan biasanya terjadi pada hubungan persahabatan yang terjalin dengan baik yang saling membantu, memahami, saling mempercayai, menimbulkan rasa nyaman dan saling mendukung satu sama lain. Dalam film 5 $\mathrm{Cm}$ ini keakraban yang begitu dekat dalam persahabatan mereka susah dan senang mereka hadapi bersama-sama, satu bisa dan semuanya pasti harus bisa, satu sakit dan semuanya juga harus ikut merasakan sakit. Saling menyemangati satu sama lain dan semuanya harus bangkit sama-sama dan apapun yang terjadi harus dihadapi bersama-sama. Itulah keakraban yang sangat menonjol dalam film $5 \mathrm{Cm}$ ini.

Nilai ketulusan dalam film $5 \mathrm{Cm}$ ini juga sangat menonjol dalam film ini karena ketulusan dalam persahabatan ini ketulusan yang begitu ikhlas. Ketulusan adalah kesungguhan atau kebersihan hati seseorang dalam memberikan sesuatu atapun ketulusan dalam bentuk persahabatan adalah ketulusan hati untuk saling mencintai dan ketulusan menolong sesama. Dalam film 5 $\mathrm{Cm}$ ada ketulusan hati untuk mencintai Negeri ini demi untuk mengibarkan sang Saka Merah putih. Dengan perjuangan yang begitu berat untuk mencapai puncak gunung Mahameru. Dengan ketulusan hati tanpa ada kata menyerah mereka sampai pada puncaknya dan ketulusan hati saling mencintai.

Dalam film $5 \mathrm{Cm}$ terdapat juga nilai kerja keras. Kerja keras adalah kegiatan yang dilakukan secara sungguh-sungguh tanpa menyerah dan tidak mengenal kata lelah sebelum target yang di kejar tercapai. Dalam film $5 \mathrm{Cm}$ kerja keras yang luar biasa yang dilakukan dalam persahabatan ini. Mereka sama sekali tidak mengenal lelah dan selalu semangat sampai apa yang ingin mereka capai terpenuhi. Kerja keras dalam mendaki gunung sampai menuju puncaknya itu sangat luar biasa sekali apalagi gunung yang di daki adalah gunung Mahameru, gunung yang paling tertinggi di Pulau Jawa.

Dalam film $5 \mathrm{Cm}$ juga terdapat nilai saling membantu. Nilai ini merupakan nilai terakhir yang peneliti bahas dalam penelitian tentang persahabatan dalam film ini. Nilai saling membantu juga sangat menonjol dalam film ini dimana dari hasil yang peneliti temukan bahwa nilai saling membantu dalam film $5 \mathrm{~cm}$ saling membantu yang penuh dengan tanggungjawab. Saling membantu adalah saling menolong antar sesama, membantu teman ataupun seseorang yang mengalami kesulitan dengan hati yang ikhlas dan penuh dengan tanggung jawab. Dalam film 
$5 \mathrm{Cm}$ ini ada rasa saling tolong menolong yaitu membantu temannya yang mengalami kesulitan. Ketika Azril mengalami kedinginan yang mengerikan mereka membantu dengan cara memeluknya bersama-sama agar Azril tidak merasa kedinginan lagi. Ketika Zafran kakinya terluka mereka berhenti sebentar untuk mengobati kaki Zafran yang terluka. Dan ketika Ian yang hampir mati karena terkena runtuhan benturan batu mereka mencoba menyelamatkannya.

Dari nilai-nilai yang peneliti angkat dalam penelitian ini sudah jelas bahwa nilai-nilai dalam film $5 \mathrm{Cm}$ sangat bermakna dan patuh di contoh dalam menjalin sebuah hubungan persahabatan karena dengan nilai tersebut kita bisa tahu bagaimana arti untuk saling setia, akrab, saling mencintai dan menjaga sebuah hubungan persahabatan.

\section{SIMPULAN}

Secara keseluruhan, persepsi siswa tentang persahabatan dalam film $5 \mathrm{Cm}$ cenderung positif dengan adanya nilainilai kesetiaan, pengorbanan, perjuangan, keakraban, ketulusan, kerja keras, dan nilai saling membantu. Persepsi siswa tentang nilai kesetiaan dalam film 5 $\mathrm{Cm}$ cenderung positif hal ini terlihat dari adanya nilai kesetiaan yang sejati yang sangat bagus untuk dipertahankan dalam menjalin sebuah hubungan persahabatan. Persepsi siswa tentang nilai pengorbanan dalam film $5 \mathrm{Cm}$ cenderung positif hal ini terlihat dari adanya nilai pengorbanan yang ikhlas dalam film $5 \mathrm{Cm}$. Persepsi siswa tentang nilai perjuangan dalam film $5 \mathrm{Cm}$ cenderung positif hal ini terlihat dari adanya nilai perjuangan yang sungguh-sungguh dalam film $5 \mathrm{Cm}$. Persepsi siswa tentang nilai keakraban dalam film $5 \mathrm{Cm}$ cenderung positif hal ini terlihat dari adanya nilai keakraban yang kompak dalam film $5 \mathrm{Cm}$ yang sangat bagus untuk dicontoh dalam menjalin sebuah hubungan persahabatan. Persepsi siswa tentang nilai ketulusan dalam film 5
$\mathrm{Cm}$ cenderung positif hal ini terlihat dari adanya nilai ketulusan yang ikhlas dan ketulusan untuk saling mencintai dalam film $5 \mathrm{Cm}$. Persepsi siswa tentang nilai kerja keras yang ada dalam film $5 \mathrm{Cm}$ cenderung positif hal ini terlihat dari adanya nilai kerja keras yang sungguhsungguh dalam persahabatannya. Persepsi siswa tentang nilai saling membantu dalam film $5 \mathrm{Cm}$ cenderung positif hal ini terlihat dari adanya nilai saling membantu dengan hati yang ikhlas dalam film $5 \mathrm{Cm}$.

\section{DAFTAR PUSTAKA}

Ardianto, E \& Erdiyana, L.K. (2004). Komunikasi Massa Suatu Pengantar. Bandung: Rosdakarya.

Arifa D. Hendra, Y \& Barus, R.K.I (2017). Persepsi Warga Lingkungan 21 Kelurahan Tanjung Mulia Tentang Tayangan Infotainment SILET di RCTI. PERSPEKTIF, 6 (2): 75-82.

Bungin, B. (2007). Penelitian Kualitatif. Jakarta: Kencana Media Group. Cangara, Hafied. 2006. Pengantar Ilmu Komunikasi. Jakarta: Rajagrafindo Persada. Dhirgantoro, Donny. 5 Cm. Jakarta: Grasindo, 2005. Print.

Effendy, O.U. (2003). Ilmu teori dan filsafat komunikasi. Bandung: PT. Citra Aditya Bakti

Irawanto, B. (1999). Film Ideologi dan Militer Hegemoni Militer Dalam Sinema Indonesia. Yogyakarta: Media Persindo.

Kriyantono, R. (2006). Teknik Praktis Riset Komunikasi. Jakarta: Kencana Prenada Media Group

Meleong J.L. (2006). Metodologi Penelitian Kualitatif. Bandung: PT. Remaja Rosda Karya

Meleong J.L. (2007). Metodologi Penelitian Kualitatif. PT. Remaja Rosda Karya, Bandung

Mulyana, D. \& Rakhmat. (2002). Komunikasi Antara Budaya: Panduan Berkomunikasi Dengan Orang-Orang Berbeda Budaya. Bandung: Remaja Rosdakarya.

Nawawi, H. (1995). Metode Penelitian Bidang Sosial. Yogyakarta: Gajah Mada University Press.

Nuruddin. (2004). Komunikasi Massa. Yogyakarta: Cespur.

Nuruddin. (2007). Pengantar Komunikasi Massa. Jakarta: PT. Raja Grafindo Persada.

Nuruddin. (2011). Pengantar Komunikasi Massa. Jakarta: PT. Raja Grafindo Persada.

Rakhmat, J. (2001). Psikologi komunikasi. Bandung: PT. Remaja Rosdakarya. 
Rakhmat, J. (2005). Psikologi Komunikasi. Bandung: Rakhmat. J. (2002). Metode Penelitian PT. Remaja Rosdakarya.

Komunikasi. Bandung: PT. Remaja Rosdakarya. 